\title{
LOS OTROS TRABAJADORES AGRÍCOLAS TRANSNACIONALES: UNA RED DE INJERTADORES MEXICANOS
}

\section{OTHER TRANSNATIONAL AGRICULTURAL WORKERS. A NETWORK OF MEXICAN GRAFTERS}

Dra. Martha Judith Sánchez ${ }^{*}$ R. Francisco Torres**

Resumen: La globalización del régimen agroalimentario ha detonado una serie de flujos migratorios transnacionales. Los más estudiados han sido los de los jornaleros de temporada que realizan los trabajos más arduos, precarios y estacionales. Los trabajadores transnacionales especializados tanto en el campo como en las diversas actividades requeridas para una industria vitivinícola globalizada no han sido estudiados. Este artículo aborda el estudio de una red de trabajadores agrícolas especializados, los injertadores. Se estudia el origen de la red en el condado de Napa y su ampliación y consolidación que ha llevado a estos trabajadores a diferentes países y continentes. Se analizan las características de esa red y las trayectorias sociolaborales de esos injertadores mexicanos así como su importancia en una industria que se basa en una economía de signos y símbolos en donde la calidad y la distinción de sus vinos es un elemento central que lleva a la creciente necesidad de esa actividad.

* Investigadora titular, Instituto de Investigaciones Sociales, Universidad Nacional Autónoma de México,mjudith@sociales.unam.mx

** Profesor del Departamento de Sociología y Antropología Social de la Universidad de Valencia, francisco.torres@uv.es 
Palabras claves: trabajadores transnacionales; injertadores mexicanos; vitivinicultura; red transnacional.

Abstract: The globalization of the agri-food system has triggered a series of transnational migratory flows. The most widely studied ones have involved seasonal day laborers, who perform the most arduous, precarious and seasonal work. Transnational workers specializing in both in the field and the various activities required for a globalized wine industry have not been studied. This article examines a network of specialized agricultural workers: grafters. The origin of the network in Napa County and its expansion and consolidation which have taken these workers to different countries and continents is studied. The characteristics of this network and the social and labor trajectories of these Mexican grafters are analyzed, as well as their importance in an industry based on an economy of signs and spaces, where the quality and distinction of their wines is a central element that has led to a growing need for this activity.'

Key words: transnational workers; Mexican grafters; viticulture; transnational networks.

\section{INTRODUCCIÓN}

La creciente globalización del régimen agroalimentario genera flujos transnacionales de capital, profesionales, know-how y mano de obra, con una diversidad de fenómenos migratorios. En el sector vitivinícola podemos distinguir tres tipos de migraciones de trabajadores asalariados transnacionales. Un primer tipo, el más numeroso, es el de trabajadores para tareas no cualificadas, en no pocos casos vinculadas a la vendimia. Un segundo tipo lo conforman trabajadores agrícolas especializados, trabajan en el campo pero realizan tareas cualificadas, como es el injerto de calidad. Un tercer tipo estaría compuesto por profesionales altamente cualificados, muy cotizados, como enólogos y otros, denominados "proficians" (Standing, 2011 citado en Tomic y Trumper, 2018).

La heterogeneidad de migraciones y de trabajadores agrícolas y profesionales transnacionales está relacionada con un mercado de trabajo crecientemente segmentado y jerarquizado por cualificación, origen nacional, etnicidad y sexo. La realidad de Napa es representativa de las zonas vitivinícolas globalizadas donde esa jerarquización 
opera en dos espacios sociolaborales distintos: la bodega y el campo. La jerarquía en bodega supone varios niveles. El más bajo y racializado lo ocupan los que limpian, trasladan, envasan y etiquetan; son mayoritariamente migrantes y varones, aunque las mujeres predominan en el envasado. Otro nivel está representado por los trabajadores de los servicios de cara al público, catas y enoturismo; suelen ser jóvenes norteamericanos y, recientemente, una minoría creciente de hijos e hijas de mexicanos nacidos y escolarizados en Estados Unidos, con contratos temporales. El personal cualificado de gerencia, administración y marketing, son norteamericanos, con predominio de los varones, con buenos contratos. Finalmente, en la cúspide de la jerarquía están los enólogos, sommeliers y chefs, principalmente varones norteamericanos pero también extranjeros, fundamentalmente europeos. Una parte de estos "proficiens", profesionales altamente calificados, muy cotizados y muy bien pagados, son transnacionales.

Entre los trabajadores del campo hay también una jerarquización interna. En el nivel más bajo los jornaleros a destajo o por temporada, inmigrantes mexicanos fundamentalmente, trabajadores racializados y temporales, con labores arduas y condiciones muy precarias. Un segundo nivel, lo constituyen los trabajadores permanentes, con algún nivel de calificación, como tractoristas, supervisores y otros ${ }^{1}$, mayoritariamente migrantes, que cubren las tareas que requieren mayor conocimiento y con salarios mejores que los jornaleros. Finalmente, encontramos un sector cualificado y con un trabajo temporal que viene a ser representado por los injertadores. La especialización de estos últimos trabajadores es reconocida y su trabajo es mejor pagado que el de todos los anteriores.

Disponemos de una amplia literatura científica, a ambos lados del Atlántico, sobre el primer tipo de migraciones de trabajadores agrícolas transnacionales, los que realizan tareas no cualificadas. Sin embargo, las migraciones de trabajadores agrícolas especializados y de "proficians" no han sido estudiadas. Si bien su número es muy reducido en comparación con los trabajadores no cualificados, su papel es muy relevante en el proceso productivo, particularmente en las zonas vitivinícolas de más prestigio, plenamente insertas

1 Heredia y Poblete (2013) incluye en este grupo a los injertadores. Nosotros no lo consideramos así ya que no son trabajadores permanentes en el caso estudiado. 
en una "economía de signos y espacios" (Scott y Urry, 1994), con ofertas selectas de turismo, gastronomía y cata (Tomic y Trumper, 2018), y estrategias de diversificación, distinción y valorización del producto (Morilla, 2001; Pan-Montojo, 2009).

Sobre la base de un estudio de caso significativo de trabajadores agrícolas especializados transnacionales, una red de injertadores mexicanos surgida en Napa California (Estados Unidos) y su evolución a lo largo de cuatro décadas, este artículo tiene tres objetivos. Primero, analizar el surgimiento y consolidación de la red de injertadores, así como su actividad y condiciones de trabajo. Segundo, captar las implicaciones de este trabajo especializado en sus trayectorias socio-laboral y vitales, así como los factores más influyentes. Tercero, contribuir a un mayor conocimiento de la diversidad y heterogeneidad de migraciones de trabajadores y profesionales transnacionales en determinados sectores agrícolas.

\section{ESTADO DEL ARTE. MARCO TEÓRICO}

En la agricultura europea, el recurso a trabajadores transnacionales temporales, además de los inmigrantes residentes en cada país, empieza a adquirir relevancia desde mediados de los años 80 (Berlan, 1986; Corrado et al, 2016), con fórmulas diversas según los países. En Francia, los contratos OIM (Organización Internacional para las Migraciones) desde los años 70 y más tarde los contratos OFII (Oficina Francesa de Inmigración e Integración) (Michalon y Potot, 2008; Décosse, 2011), el Seasonal Agricultural Workers Scheme (SAWS) británico desde mediados de los años 80, el Saisonarbeiter alemán de los años 90 (Miller y Martin, 1982) y los Programas de Contratación en Origen desde primeros del siglo XXI, poco utilizados en su modalidad francesa y con gran éxito en el caso español (Gordo y García, 2009; Achón, 2011; Torres et al, 2014), han sido otras tantas fórmulas para regular la migración temporal agrícola, con obligación de regresar al país de origen (Lamanthe, 2015). Además, algunas de estas modalidades de contratación se han sesgado por género, nacionalidad y tipo de cultivo, en función de las estrategias empresariales para conseguir una mano de obra flexible, dúctil y poco reivindicativa (Morice y Michalon, 2008; Moreno, 2012; Reigada, 2015). En la segunda década del siglo XXI se mantienen 
algunas de estas formas de contratación al mismo tiempo que se ha consolidado una importante migración transnacional entre trabajadores de Europa del Este y diversos países de Europa Occidental, dadas las sucesivas ampliaciones de la Unión Europea que han extendido el área de libre circulación europea (Viruela 2016). Otra modalidad la constituyen los trabajadores desplazados extracomunitarios, con creciente relevancia en la agricultura francesa de trabajadores residentes en España y movilizados por Empresas de Trabajo Temporal (Mésini, 2015).

En América del Norte, el grueso de la literatura aborda la migración de mexicanos hacia las actividades agrícolas en Estados Unidos que tanto por su volumen como por su historicidad representa el flujo migratorio más importante. El desarrollo de la agricultura capitalista, principalmente en California, ha requerido de un contingente importante de trabajadores con diversas modalidades de reclutamiento a lo largo del tiempo. En el contexto de la Segunda Guerra Mundial mediante el Programa Bracero (García y Griego, 1988; Durand, 2007; Vézina 2015). Al término del programa tanto los rancheros como los trabajadores ya tenían sus propias redes para conseguir la mano de obra necesaria los primeros y los trabajos que necesitaban los segundos. Ese periodo se caracterizó por ser una migración circular, en el sentido ya clásico de Zelinsky (1971), los mexicanos llegaban en las temporadas pico de empleo y regresaban a sus lugares de origen al terminarse los periodos de cosecha. Otros hacían las llamadas "corridas", circuitos migratorios en diferentes zonas agrícolas de la Unión Americana. El cambio en las actividades agrícolas que ampliaron los periodos de empleo y las crecientes restricciones en la frontera hicieron que los varones, primero, y sus familias, después, se fueran asentando. Elemento decisivo en ese arraigo fue la regularización mediante el IRCA ${ }^{2}(1986)$ y el SAW ${ }^{3}$ (Martin et al, 1988; Durand, 2014). El primero regularizó la situación de 2,3 millones de mexicanos. Esa etapa que llevó a una sobreoferta de trabajadores inicia su cambio a finales de la década de los noventa con la creciente criminalización de la migración, el reforzamiento en la frontera y más recientemente con el encarecimiento y el riesgo del cruce fronterizo propiciando una situación de escasez de trabajadores y el aumento en las visas de trabajo

Ley de Reforma y Control de la Inmigración.

Programa de Trabajadores Agrícolas Especiales. 
temporal, H2A y H2B para paliar esa situación (Durand, 2015; Trigueros, 2015).

A lo largo de más de un siglo, el reemplazo étnico ha estado siempre presente como mecanismo de control del mercado de trabajo y de los precarios salarios. En California, los chinos, filipinos y americanos empobrecidos fueron sustituidos por mexicanos, principalmente mestizos, éstos a su vez, por mexicanos hablantes de lenguas indígenas, y recientemente de manera incipiente, por centroamericanos (Mines, 2013; Sánchez, 2007; Zabin et al, 1993). Diferente es el caso para Canadá. El programa de trabajadores agrícolas temporales (PTAT), orientado principalmente a los trabajadores del Caribe, fue incrementando la presencia de los mexicanos como también sucedió con otros programas privados de reclutamiento de mano de obra agrícola (Esteban y López-Sala, 2010; Verduzco, 2015; Preibisch, 2015).

La literatura antes mencionada se refiere a trabajadores agrícolas transnacionales para tareas no cualificadas. Si bien realiza valiosas aportaciones al conocimiento de la inmigración en la agricultura globalizada, no se abordan las redes de trabajadores especializados y de profesionales transnacionales, sus similitudes (la movilidad) y sus diferencias (inserción en la estructura productiva, percepción social, etnicidad, calidad de la movilidad, entre otros).

Como sucede con otros trabajadores transnacionales, los grupos de injertadores mexicanos que estudiamos se articulan en y conforman una red migratoria transnacional, entendida como el conjunto de relaciones interpersonales basadas en relaciones de parentesco, amistad, origen, $\mathrm{u}$ otro aspecto común, que supone el intercambio de informaciones, bienes y servicios, y que conforman campos sociales transnacionales. En esta definición articulamos las teorías de redes y del transnacionalismo. Popularizado en la década de los años 80 , el concepto de red daba una mejor explicación a diversos aspectos de los flujos migratorios, como su relativa dinámica propia, la desigual distribución territorial o las trayectorias específicas de determinados grupos (Portes, 1995; Castles, 2000). Como sabemos, no toda migración o movilidad internacional mantiene un carácter transnacional (Waldinger, 2013). En el caso de los injertadores mexicanos, el carácter transnacional de la red se ve reafirmado por las conexiones renovadas entre origen y destinos, la persistencia de dinámicas y prácticas que ratifican este carácter y la conformación de un campo migratorio entre El Grullo (México), Napa (California) 
y otros puntos. Es decir, las características centrales del transnacionalismo (Gilck Schiller et al, 1992; Portes et al, 1999).

Como ocurre en otras redes migratorias, la potencia de la red de injertadores mexicanos reside en su capital social. De acuerdo con Bourdieu (1980) y Portes (1995), entenderemos capital social como el conjunto de recursos de que dispone un individuo o grupo en función de sus relaciones con otros individuos y grupos. El interés del capital social es su convertibilidad (Bourdieu, 1980) en acceso a trabajo, a vivienda, a crédito y/o a relaciones significativas, gracias a las posibilidades que proporciona la red.

Aunque, los injertadores mexicanos de nuestro estudio presentan diferencias en términos de nivel de escolaridad, experiencia laboral y otros factores, lo fundamental para todos ellos es que participan del capital social de la red que les posibilita trabajar en una tarea cualificada, como es el injerto de calidad, y mejor remunerada que otras actividades agrícolas.

\section{METODOLOGÍA}

Nuestra investigación se ha realizado a lo largo de distintos períodos en los últimos veinte años, combinando métodos cuantitativos y cualitativos. Entre los primeros, se ha trabajado con diversas fuentes estadísticas (USDA, 2012, 2014). Además, nuestro trabajo ha tenido una amplia dimensión cualitativa, con una diversidad de técnicas. En un primer período, entre 1997 y 1999, en el marco del proyecto "Process of recreation and creation of new identities among the grape farm workers of the Napa and Sonoma Counties"4, se realizaron 235 cuestionarios $^{5}$ y 8 historias de vida, a diferentes actores, entre otros a injertadores. Sobre esta base, se retomó el tema quince años después con el proyecto "La expansión de zonas vitivinícolas y el trabajo inmigrante. Estudio comparativo en dos países: Estados

\footnotetext{
4 Proyecto UC.Mexus-Conacyt, 1998-1999. Responsable: Martha Judith Sánchez Gómez.

5 Se obtuvo información sobre características sociodemográficas de los migrantes y sus grupos familiares, trayectorias migratorias en México y Estados Unidos, trayectorias laborales y percepción de problemas en espacios laborales y sociales.
} 
Unidos y España" con períodos de trabajo de campo entre 2014 y 2017, en los que se realizaron 38 entrevistas en el condado de Napa y en El Grullo (Jalisco), así como en España (Ribera de Duero y Rioja) y Francia (Provence), para captar la situación actual, trayectorias de los injertadores y los contactos con empresas en esos paí$\mathrm{ses}^{7}$. Además de las entrevistas, unas individuales y otras grupales, se ha realizado observación participante, en reuniones comunitarias y eventos de migrantes mexicanos en Napa. Los cuestionarios y las entrevistas se realizaron en Calistoga Farm Workers Housing y en el River Ranch Farm Workers Housing en Santa Helena (albergues de trabajadores), sedes de asociaciones, bares y, eventualmente, en casa de los entrevistados. Seis de las entrevistas se realizaron por Skype (profesionales franceses y algunos injertadores que estaban en sus comunidades de origen).

\section{EL TERRITORIO, EL CONTEXTO Y LA ACTIVIDAD. EL VALLE DE NAPA Y EL INJERTO}

El Valle de Napa es, sin duda alguna, uno de los referentes en el mundo del vino. Ubicada en el norte de California, estado que produce el 90\% del vino de Estados Unidos, Napa contribuye con el 4\% del total de esta producción, pero con el $27 \%$ del valor de las ventas del vino del estado. Estas elevadas ganancias se deben tanto a la excelencia de sus vinos, que han ganado numerosos concursos internacionales, como a la relevancia de un enoturismo de altos ingresos (USDA 2012, 2014); en 2005 Napa recibió 4,7 millones de turistas que gastaron 1,3 billones de dólares (McLean, 2013).

Históricamente, las tierras del Valle de Napa se dedicaban a ganadería, frutales y algunos viñedos. En la actualidad los viñedos ocupan la casi totalidad de las tierras de cultivo, el 99.24\%, y suponen el $99.16 \%$ del valor del producto bruto del epígrafe, cultivo de frutas y nueces donde se incluyen (USDA, 2014).

\footnotetext{
6 Proyecto Conacyt, 2013-2018. Responsable: Martha Judith Sánchez Gómez.

Para guardar la confidencialidad se cambiaron los nombres de los entrevistados. En las citas se indica el seudónimo y el año de realización de la entrevista.
} 
En la historia de transformaciones de ese Valle resaltaremos, por su relevancia, dos etapas. La primera etapa está marcada por la filoxera ${ }^{8}$, que junto con la Ley Seca y la depresión económica en EE. UU., llevó prácticamente a la destrucción de los viñedos en las primeras décadas del siglo $\mathrm{XX}$, aunque en décadas posteriores se recuperó una modesta producción (Nichols, 2006). Otra etapa muy significativa, se inició a finales de los años 80. En esos años gran parte de las tierras de frutales se habían transformado en viñedos y Napa despuntaba como zona vitivinícola de gran prestigio y con posibilidades de generar grandes ganancias; además la investigación y experimentación en el campo vitivinícola conocían importantes avances. En ese contexto se desató otra plaga de filoxera con lo que se debía arrancar las viñas y plantar otras nuevas o injertar las cepas, afectadas o no. Es así como el injerto y la necesidad de trabajadores conocedores de esa técnica creció en importancia. En palabras del pionero mexicano en esa actividad "a finales de los ochentas se tuvo que cambiar todo el valle de Napa porque llegó la filoxera... había muchísimo trabajo" (Sr. Palma, 1997). Estos primeros injertadores formaban parte de la migración mexicana que, en la década de los ochenta, empezaba a contar con familias asentadas y con redes transnacionales entre Napa y diferentes estados de la república mexicana, principalmente Michoacán, Jalisco, Zacatecas y Oaxaca (Sánchez, 2004), iniciando el proceso de conformación de comunidades transnacionales.

El injerto es una técnica ancestral utilizada en diversos cultivos. El Sr. Palma señala que los italianos antecedieron a los mexicanos en el trabajo de las viñas y que introdujeron el injerto en la zona. En el caso de la vid, el injerto se utiliza para plantaciones nuevas, en campos afectados por la filoxera $\mathrm{u}$ otras plagas, o bien para mejorar la calidad de las viñas, prolongar su vida productiva, incrementar la producción y/o modificar la variedad a fin de adaptarse al gusto cambiante del mercado. El Sr. Palma fue quien introdujo y popularizó este último tipo de injerto.

En esos años el trabajo fuerte era de verano de raíz y poco de cambio.... Realmente Santiago [Sr. Palma] empezó a poner de moda ese cambio de variedad porque era otra opción, en vez de sacar la viña y plantar nueva, venía esa opción que era más

8 Plaga generada por insectos que atacan las hojas y los filamentos de las raíces de la vid. 
económica y más efectiva, nada más se pierde un año de producción. Al siguiente año ya está produciendo. Y al quitar la viña vieja hay que quitar mangueras de riego, alambres, postes, todo el sistema y hay que esperar como unos tres o cuatro años para empezar a producir y muy costoso (Luciano, 2016).

Aunque desde mediados del siglo XX se ha generalizado el injerto mecánico, más barato, con buenos rendimientos y que no requiere personal especializado, se considera que el injerto manual ofrece mejores resultados, mayor resistencia a diversas enfermedades del leño (yesca, decaimiento y otras) y un marchamo de prestigio. En la creciente competencia del sector superior de bodegas, entre otros aspectos destacando los significados asociados al vino que producen (cualidades atribuidas, prácticas de producción, características del lugar), el injerto manual es otro signo más de distinción. En esta situación, el injerto manual de calidad se conformó como un nicho de trabajo muy vinculado con la creciente competencia, la diferenciación del producto y la rápida adaptación a las modas que caracterizan la globalización del vino (Morilla, 2001; Pan-Montojo, 2009).

Hay demanda de injerto porque el vino es como la moda de la ropa, entonces ahorita pegan unas variedades y se venden muy bien y hay unas variedades que no se venden, entonces para hacer un cambio...le puedo decir que allí en California hace 12 años... quitamos cabernet y pusimos merlot en una finca, al lado de Sonoma. A los 10 años volvimos a quitar el merlot y volvimos a poner cabernet ... a veces a los 10 años, lo que se quitó se vuelve a poner porque vuelve a cobrar fama o prestigio esa variedad que se había quitado (Camilo, 2007).

\section{RESULTADOS Y DISCUSIÓN}

\subsection{Los pioneros y el inicio de la red de injertadores}

Los señores Santiago Palma y Saúl Lara, originarios de El Grullo (Jalisco), fueron según todos los entrevistados los creadores de la red a primeros de los años 80. Aprenden a injertar, se independizan de las empresas para quienes trabajaban y empiezan a ofrecer directamente el servicio. Para afrontar la creciente demanda reclutan y 
enseñan a otros paisanos suyos de El Grullo, pero también de comunidades cercanas. En palabras de un injertador veterano

Cuando empezó el injerto aquí en el valle hubo dos personas de mi pueblo que aprendieron ese trabajo y ellos fueron aprendiendo [quiere decir enseñando] a los demás, Saúl Lara que ya falleció y el otro más importante, Santiago Palma, también de El Grullo (Manuel, 2015).

El señor Palma llegó en la década de los sesenta, con 20 años, a la ciudad de Santa Helena, condado de Napa, donde ya había mexicanos. Joven y pobre, sus padres no tenían tierras y él trabajaba en la construcción, le mueven sus deseos de mejorar. Conoce un amigopaisano en Santa Helena y cuando llega entra a trabajar en Emmolo Nursery, un vivero donde aprende el trabajo que ahí se realizaba. Aprende también a injertar y con la ayuda de los dueños del lugar regulariza su situación migratoria.

Empecé a aprender de todo, desde cómo hacer una planta. En el mismo año me empezaron a enseñar a injertar un poquito. Los primeros años era poquito lo que hacíamos. Nada más hacíamos lo que le llamábamos "de verano" o en inglés le llaman summer pruning. Ya después en el 75 o algo así se empezó con el spring graftin. Ya empecé yo a aprender más y más. En el camino fui aprendiendo (Santiago Palma, 1998).

En esos años asiste también a clases de inglés algunos días a la semana. Cuando aprende a injertar lo mandaban a realizar esa labor en el mismo condado o en lugares cercanos, como Ukiah. Más tarde, se independiza del vivero y oferta sus servicios, y los de los trabajadores a los que ha ido enseñando. Conforme fue dándose a conocer y aumentó su prestigio, se amplió la demanda y para atenderla aumentó el número de trabajadores, hasta 30 entre injertadores y ayudantes. Su éxito se ha basado en la calidad de su trabajo y eso es lo que valora el segmento alto de bodegas que le contrata.

Él fue creciendo con su gente, con su cuadrilla, con su compañía, porque empezó a enseñar gente, no fue egoísta, él empezó a enseñar gente (Joel, 2017).

El señor Palma se encarga de conseguir trabajadores, enseñar a injertar a los nuevos, organizar el trabajo, ofrecerlo y 
responsabilizarse por los resultados. Él y los injertadores más experimentados se implican en la enseñanza del injerto. Su palabra es un relevante aval profesional para su gente.

Mire, yo le voy a decir una cosa [...] el árbol que se desprenden todas las ramas de que se han hecho de los injertadores. Hay una persona aquí, bueno, lo conoce ¿verdad?, Santiago Palma [...] y de él empezamos, con él, y todos, todos en el Grullo hay muchas personas que se dedican a eso y aquí también. Muchos, muchos somos discípulos de él, o sea él es el maestro de todos nosotros (Luciano, 2017).

Hay dos elementos que son centrales en el trabajo que realiza. La primera es que el acceso a la mano de obra ha sido a través de sus redes de parentesco principalmente y posteriormente de paisanazgo, iniciando con los de su comunidad y ampliándolo con los de las comunidades vecinas y de otros estados del país. El segundo elemento es la enseñanza en el oficio. Saber injertar y hacerlo muy bien se convierte en un capital de la red y la base de su éxito. El Sr. Palma comparte ese capital con los miembros de la red, asume la enseñanza de las mejores técnicas, al tiempo que esa enseñanza y la continua supervisión de los trabajadores se hace necesaria en una labor tan especializada como es el injerto de calidad.

A mediados de los años 90, la red está plenamente conformada con sus rasgos actuales. Respecto a sus miembros, la red cumple tres funciones básicas: reclutamiento, enseñanza del oficio y, mediante sus contactos y el prestigio conseguido, inserción en los circuitos profesionales del injerto de calidad, primero en Estados Unidos y más tarde en Europa y otros países. Gracias a la actitud "no egoísta" del señor Preciado que destacan los entrevistados, saber injertar es un activo que los trabajadores han adquirido con él; bien sea para continuar trabajando en alguno de sus grupos, para hacerlo de forma independiente o por cuenta de contratistas.

\subsection{La ampliación de la red y el carácter transnacional}

En la década de los años 80 y posteriores, el señor Palma y sus trabajadores han injertado en diversas zonas y estados de Estados Unidos. En California además de Napa, han trabajado en los condados de Monterrey, Fresno, Kern y Yolo. En el estado de Nueva York 
en Long Island. Sus contactos internacionales se iniciaron, también, pronto. En 1981, Alain Dupont, viticultor francés y fundador de una importante empresa francesa de servicios vitivinícolas, viaja a Napa, "descubre el reinjerto y sus fantásticos resultados y decide repatriar esa técnica a Francia". Además, durante este viaje Dupont "conoce a Santiago Palma y a su grupo de injertadores, que destacaban por su trabajo de calidad" (Gerard, 2015). En 1986, "el sr. Dupont, francés, me contrató para una winery de unos franceses en Texas" (Santiago Palma, 2016). Dos temporadas más tarde les propone ir a trabajar a Francia a una zona cerca de Burdeos; el señor Palma con muchos compromisos en Napa no se desplazó, pero si envió a tres de sus trabajadores. Al siguiente año, él fue a Francia.

Las migraciones temporales a Europa se iniciaron a primeros de los años 90 y continúan en la actualidad. Aunque hay otros injertadores latinoamericanos en Europa, la continuidad de los viajes indica la existencia de una demanda no cubierta, el carácter muy competitivo de los injertadores mexicanos, el prestigio adquirido y, principalmente, la aceptación de condiciones y ritmos de trabajo que los trabajadores nacionales no estarían dispuestos a aceptar. Preguntado al respecto, nuestros entrevistados señalan que ellos trabajan más rápido, de forma ininterrumpida a lo largo de la temporada ya que les interesa maximizar sus ganancias durante su estancia. Además, afirman, las empresas europeas no suelen formar a otros trabajadores para no perder cuota de mercado. Así lo expresan dos de nuestros entrevistados, tío y sobrino:

Por la experiencia de Napa... ellos hacen el trabajo muy despacito y cuando hacen de cuña ahí se durmió (José, 2015).

[...] la compañía no enseña a personas allá para que sean injertadores, uno, porque le van a brincar los trabajos a él mismo, ¿no? [...] y dos, el ritmo de trabajo y el horario de trabajo que uno se pone no lo van a hacer personas que vivan ahí mismo pues (Alfredo, 2015).

En las migraciones a países europeos, los primeros injertadores mexicanos "residían en California y venían desde allí. Los siguientes, los actuales, parientes y amigos de Santiago, vienen directamente de su pueblo, El Grullo" (Gerard, 2015). Debido al reforzamiento de la frontera y la dificultad de encontrar trabajo en Napa sin documentación, el señor Palma y sus trabajadores acordaron que los que tenían papeles o residían en Napa continuarían con esa actividad en 
Estados Unidos. A los que carecían de documentos el Sr. Palma los enviaría a los países europeos.

En la actualidad, continúan trabajando con la empresa francesa de servicios vitivinícolas, ahora dirigida por el hijo del fundador, con contratos en diversos países europeos. Aunque el señor Palma ya no se desplaza, ya que prioriza su actividad en Napa, sí manda a sus trabajadores

Yo lo que le dije fue - yo no puedo estar yendo, si quieres el trabajo puedo prestarte gente de los míos. Aunque no me des parte ni nada. Pero ya ellos que se encarguen. Es mucho problema [habla de Europa], porque hay que ponerlos en hotel, donde duerman, darles de comer, moverlos, todo. Aquí [habla de Napa] cada quien se mueve, es mucho más fácil. Aquí a los trabajadores yo nada más les digo donde va a ser y se mueven. Cada quien tiene su automóvil (Santiago Palma, 2016).

La relación con la empresa francesa de servicios se ha mantenido a lo largo de décadas, en una relación de interés mutuo, pero desigual. La empresa proporciona al señor Palma y a su gente trabajo en Europa con el segmento alto de las bodegas europeas. Por otro lado, como destacaba uno de los trabajadores encuestados, el saber hacer de los mexicanos ha sido una de las bases del rápido crecimiento de esta compañía de servicios vitivinícolas francesa, hasta situarla entre las más conocidas y prestigiosas de Europa.

Sí, sí, ha crecido mucho. Nosotros cuando fuimos, Santiago [Sr. Palma] mandó su mejor gente, en realidad mandó a su gente de experiencia y los de más confianza. Santiago fue parte fundamental del prestigio de esa compañía cuando empezó y pues ya actualmente se fue relacionando fue creciendo y fue parte fundamental del crecimiento de esa compañía (Camilo, 2017).

En la última década, la red de injertadores mexicanos ha diversificado sus contactos transnacionales. Mantienen la relación con la empresa francesa para los trabajos en Francia, Italia y otros países, al tiempo que establecieron contactos en España. El dueño de la compañía francesa los contacta con una empresa de servicios vitivinícolas en España, radicada en la Rioja y constituida en el 2000, interesada en la técnica del injerto y ofrecerla en España. Desde mediados de la primera década del siglo XXI hasta la actualidad, esa compañía ofrece servicios de injerto con mexicanos de la red que estudiamos. 
Si bien la mayoría de los injertadores trabajan contratados por alguna de las dos compañías antes mencionadas, unos cuantos han explorado un camino más independiente. Estos trabajadores consiguen directamente sus clientes, empresas y/o bodegas y obtienen las visas de trabajo en España con una empresa de servicios agrarios, distinta a la anterior. Esto es, la empresa oferta el trabajo de injerto y les consigue las visas y ellos le abonan un porcentaje de las ganancias.

Desde finales de la década de los ochenta hasta la actualidad, conforme se extendía su prestigio, la red de injertados mexicanos ha ido ampliado los lugares a donde han ido a trabajar (véase mapa). En Europa los destinos son diversos: la Toscana en Italia; varias zonas vitivinícolas francesas; Ginebra en Suiza; zonas vitivinícolas del Rhin en Alemania; Portugal; y una diversidad de DO y zonas vitivinícolas en España. Además de Europa, nuestra red de injertadores también ha trabajado en Chile, Nueva Zelanda y recientemente en México en San Luis Potosí.

\section{FIGURA 1}

\section{RUTAS DE TRABAJO DE LA RED DE INJERTADORES TRANSNACIONALES MEXICANOS}

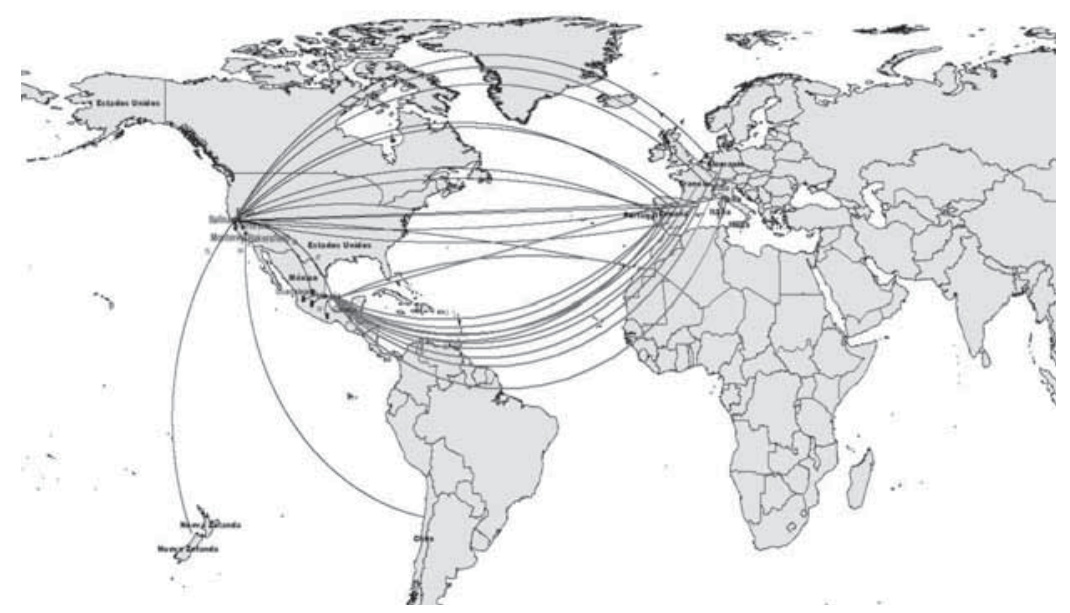

Fuente: elaboración propia con base en las entrevistas realizadas. 
Los ingresos que devengan los trabajadores son menores en México y en Chile que en los países europeos. En Chile el señor Palma decidió enseñar a los trabajadores de ese país ya que no les convenía seguir por lo bajo de los salarios. En México hace el trabajo por menos dinero, nos comenta que pensaba "soy mexicano, en mi país no he hecho nada de esto. Me gustaría [hacerlo]" (Santiago Palma, 2016).

\subsection{El trabajo y las condiciones de trabajo}

El injerto manual que realizan nuestros injertadores tiene dos modalidades fundamentales que ellos denominan de cambio y de raíz. En el primer caso, también denominado sobre-injerto, se injerta en la parte aérea de una planta previamente injertada, normalmente en el vivero, con el fin de cambiar la variedad. El injerto de raíz se realiza en la base del pie cimarrón, americano o de otro tipo, ya bien arraigado en el campo. En este caso se considera que el injerto presenta menos fallos, ofrece cosechas más pronto y tiene más longevidad. Injertar es un trabajo duro, en todas sus modalidades, aunque el injerto de raíz se considera el más penoso para el trabajador.

Las plantas [injerto] de raíz hay que hacerlas hincado en tierra y acabas con las rodillas mal, aunque lleves un cojín para apoyar [...] es más pesado, por lo hincado, y además cuando hace calor es mucho más caliente al estar hincado (Luis, 2017).

El estricto control de la calidad del trabajo es básico para el cumplimiento del contrato y para la continuidad de la red, para asegurarse futuros contratos. Cada injertador realiza y se responsabiliza de una fila o varias filas de cepas, "firma su fila" (Santiago Palma, 2015). El éxito de su trabajo y su ritmo, básico para su sueldo, depende de su pericia pero también de la labor de su "pala", el ayudante del injertador. El injertador realiza el injerto propiamente dicho mientras que el ayudante le prepara la tarea o la finaliza.

Son varios trabajos, algunas veces íbamos atrás poniendo las cintas, ellos injertaban y nosotros poníamos las cintas, otras veces delante cortando las plantas y cuando terminábamos poníamos cintas... cuando son plantas de raíz, de las chiquitas, tenemos que escarbarlas con la pala [...] ahí quitarles la tierra 
alrededor de la planta, unas 400 plantas, y eso lo hacíamos desde que empezaba casi hasta mediodía y después a tapar el injerto con tierra (Luis, 2017).

La buena compenetración entre injertador y su ayudante es básica y ambos están interesados en conseguirla. No sólo para realizar el máximo de plantas por hora; el ayudante además espera que el injertador le vaya instruyendo para, después de un tiempo, realizar sus tareas. Muchas veces, el injertador tiene lazos de amistad o familiares con el pala a quién instruye. "Eso va por generación, si es tu amigo te va enseñando" (Manuel, 2015). Además, el ayudante debe tener una actitud despierta, fijarse en los veteranos más hábiles e ir practicando por su cuenta.

A mí me enseñó él, mi tío me dio unas clasesitas [...] antes vas practicando, vas con una navaja, cogíamos varitas de las que ya no sirven, que ellos tiraban, y vas practicando [...] primero me enseño mi tío Santiago y vas viendo los mismos compañeros" (Luis, 2017).

Las condiciones concretas de trabajo, los meses de ocupación, las fórmulas de contratación, varían según los países y particularmente entre Estados Unidos y Europa.

En Estados Unidos, hay una doble temporada de injerto: durante la primavera, de abril a junio, y posteriormente, dos meses cortos, de finales de agosto a primeros de octubre. En Estados Unidos, a diferencia de Europa, se les demanda tanto el injerto de cambio como de raíz. El sueldo, considerando que se trata de un trabajo agrícola, es alto y puede establecerse por hora o por planta. En Napa se paga "entre 22 y 24 dólares la hora y por planta 1,20 dólares [...] por planta se gana más, estás haciendo un promedio de 450 a 500 plantas al día [...] si lo manejas por planta estás ganando arriba de 500 dólares" (Alfredo, 2015), aunque lo más común es el pago por hora. Si bien el salario es más alto en este país la contrapartida es que el trabajador debe pagarse el traslado, sea desde México o desde otra localidad de California, así como asumir el conjunto de sus gastos (viaje, alojamiento, comida y transporte). En Napa y otras zonas de Estados Unidos, nuestros injertadores mexicanos tienen mejor sueldo y mejores condiciones que los trabajadores vitivinícolas de la vendimia u otras tareas estacionales. Sin embargo, tienen en común la estacionalidad del trabajo, la racialización (el injerto es un trabajo 
de mexicanos), la dureza del trabajo y el desgaste físico que supone y las escasas perspectivas de mejora sociolaboral.

Además, el trabajo en Estados Unidos se ve afectado por el estatus migratorio de los injertadores, con una diversidad de situaciones. Diversos injertadores tienen documentos de residencia en Estados Unidos, otros ingresan desde México para las temporadas de injerto con visas de trabajo, pero otros lo hacen con visado de turista. Aunque varios de nuestros entrevistados afirman haber ingresado y trabajado con visado de turista durante años sin problemas, a partir de 2014 se endurecieron los controles y, al menos, tres injertadores fueron deportados.

[...] todos los años que entré no tuve problemas, eso fue el último año, no sé qué pasaría con el gobierno, entre los partidos ahí...ese año, 2014, cogieron mucha gente ya,... había tres injertando con visa [de turista] cogieron uno, luego otro y yo fui el último que cogieron [...] y ya nos mandaron 5 años de castigo (Luis, 2017).

La temporada europea es más corta que la estadounidense, únicamente tres meses, de abril a finales de junio, y el tipo de injerto es fundamentalmente de cambio. En los circuitos europeos que conocemos, el injerto lo realizan mexicanos pero también argentinos y uruguayos, y en muy menor medida algunos trabajadores autóctonos (españoles, franceses). Aunque en ocasiones estén contratados por la misma empresa o bodega, los grupos de injertadores se organizan por nacionalidad. Nuestros injertadores suelen trabajar en varios países en cada viaje, primero en los más meridionales (España, Italia y sur de Francia) para posteriormente hacerlo en los más septentrionales (Alemania, Inglaterra). Si bien, el sueldo en Europa es inferior a lo que se abona en California, "95 centavos de dólar por planta” (Miguel, 2017), se les paga el viaje, el alojamiento y la comida, así como el transporte con chofer-guía a las diferentes zonas de trabajo. Igualmente, se les tramita el permiso de trabajo con el correspondiente seguro. Como destacaba uno de los injertadores deportados de Estados Unidos:

También nos dan el permiso, prácticamente no pones un peso de tu bolsa [...] y el dinero es prácticamente libre, ¿no?, eso es lo bueno de ir a Europa y a la vez vas seguro porque vas con un permiso y aquí en EE. UU. vas de ilegal, migración te puede agarrar y quitarte los papeles (Luis, 2017). 
El sueldo y las condiciones de vida (alojamiento, transporte, guía) de los injertadores son superiores a los de otros trabajadores agrícolas temporales. Sin embargo, dada su condición de migrantes, no gozan de todos los derechos reconocidos al resto de trabajadores, en concreto las coberturas de Seguridad Social, y reciben el mismo pago por hora aún cuando trabajen más de ocho horas diarias y los fines de semana. Los injertadores cotizan a la Seguridad Social de cada país, ellos como trabajadores y la empresa de servicios o bodega como patronos. Sin embargo, dado que no hay convenios de reconocimiento mutuo de derechos laborales entre los países europeos y México y Estados Unidos, las coberturas ganadas en Europa o Estados Unidos no tienen efecto en sus países de origen. Como señala uno de los empleadores, "se paga la cotización social, pero no son cubiertos cuando vuelven... es una injusticia, los marroquíes sí, y éstos (mexicanos) no" (Gerard, 2015).

Tanto en Europa como en Estados Unidos nuestros grupos de injertadores trabajan sin descanso semanal, a un alto ritmo. En nuestras entrevistas los injertadores afirmaron que si bien es un trabajo con ventajas en relación con el trabajo jornalero, les gustaría realizarlo con las condiciones y salarios que se establecen en cada país, sin embargo trabajan sin descanso, como el tradicional "trabajo a destajo" de los países mediterráneos. En esas condiciones los injertadores tratan de optimizar la temporada del injerto, en tanto que los viticultores y las empresas de servicios agrícolas aunque abonan buenos salarios reducen sus gastos respecto a si se aplicara el convenio agrario (que contempla el descanso semanal y el pago mayor por las horas extras).

En Estados Unidos y Europa trabajamos diario, solamente que llueva mucho, que no podamos trabajar por una tormenta fuerte o que por x razones, los sarmientos no los llevaron [...] fuera de eso, trabajamos diario [...] hemos tenido temporadas que hemos trabajado corrido, sin parar un día (Luis, 2017).

\subsection{Los injertadores y sus trayectorias sociolaborales}

Como hemos visto, la red de injertadores surgió alrededor de trabajadores oriundos de El Grullo y residentes en Napa. Dado el éxito obtenido, el atractivo del trabajo y la edad avanzada de muchos de los pioneros, la red se ha ampliado y se ha diversificado la procedencia de sus miembros. 
Muchos de El Grullo se retiraron, porque están muy mayores, pero hay injertadores de El Grullo [...] hay injertadores de Oaxaca, de Natividad, de Tonalá y de San Marcos Arteaga, y de Michoacán, un pueblo que se llama Atacheo (Manuel, 2015).

Todos nuestros entrevistados han ingresado en la red por lazos de parentesco, amistad y/o paisanaje. Algunos injertadores se han incorporado a la red en México; otros, lo han hecho en Napa, actualizando sus contactos en territorio norteamericano, en muchos casos ante las dificultades de otro tipo de inserción laboral. De acuerdo con nuestras entrevistas, podemos establecer tres tipos de trayectorias laborales previas.

Un primer tipo, sería aquellos injertadores que tras períodos más o menos largos desempeñando otros trabajos, duros o mal pagados, en México o en EE. UU., recurren a sus contactos para hacerse injertadores. Uno de nuestros entrevistados, con más de veinte años como injertador, trabajó durante 10 años en el circuito de la lechuga en California (Salinas, Valle Imperial, Coalinga, Huron) que rememora como un trabajo bien pagado pero muy duro. "Teníamos muchos beneficios, estoy hablando de los años 80 , teníamos bonos, teníamos vacaciones, pagaban festivo... estábamos bien" (Manuel, 2015). Más tarde, la generalización de los contratistas y el deterioro de las condiciones laborales, la dureza del trabajo y la edad, hicieron que activara sus contactos con sus paisanos de El Grullo. "El trabajo que yo sabía hacer era para gente joven y yo ya había cumplido mi edad y me lo dejé $[\ldots .$.$] y empecé como pala, peón de injertador,$ en Napa" (Manuel, 2015). En otros casos, previamente se ha trabajado en construcción, mantenimiento, hostelería u otros sectores. Un segundo tipo de injertadores se trata de jóvenes, con contactos familiares directos con miembros de la red, y para los que el trabajo como ayudante de injertador constituye su primera experiencia laboral en Estados Unidos. "Yo llevo 11 años en el injerto, con mi tío, te vas incorporando a los mismos grupos" (Alfredo, 2015).

El tercer tipo lo constituyen profesionales, con trabajo como tales en México, que combinan su trabajo y la campaña de injerto, considerada como una importante fuente de ingreso extra. "Inclusive un hermano de él, que era ingeniero agrónomo... otro doctor que era médico municipal, pedía permiso, ganaba dinero y se regresaba..." (Manuel, 2015). Estos profesionistas eran una parte considerable de los injertadores en la década de los 90. 
[...] estudié la carrera de técnico agropecuario [...] en la Universidad de Colima [...] trabajé en la Secretaría de Recursos Hidráulicos, hoy actualmente es SAGARPA ${ }^{9}$ [...] mi cuñado Santiago Palma, él ya tenía tiempo allá y se dedicaba a eso y en una venida me dijo - si gustas ir allá para que conozcas y ya si te agrada, pues hay trabajo y puedes combinar la Secretaría con aquello- . Y una vez por medio de mi trabajo conseguí una visa de turista y es cuando fui por primera vez. Me gustó mucho por estar relacionado con mi carrera y con lo que a mí me gusta que es el campo. Entonces, desde esa vez, todos los años saco un permiso de 4 meses o 6 meses en la Secretaría, un permiso económico sin derecho a goce de sueldo y me iba a trabajar a California (Luciano, 2017).

En todo momento hablamos de injertadores ya que se trata de grupos de varones exclusivamente. Preguntados sobre la ausencia de mujeres, constatamos opiniones diversas entre nuestros entrevistados. En unos casos, se considera que es un trabajo duro que las mujeres no pueden realizar.

[...] no, no hay [mujeres]. Han querido muchas allá, pero es que las ramas de uva tienen un... una callosidad muy dura, hay variedades que de plano uno tiene que agarrar aire y dar un corte hasta la mitad, volver a agarrar aire y hacer el corte completo para terminar el corte. Entonces para una mujer es demasiado duro, es más, no pueden sacar las yemas, habrá alguna, pero es un trabajo muy duro para una mujer (Luis, 2017).

En claro contraste, otro de los entrevistados afirmaba:

[...] me he encontrado con cuadrillas de mujeres que hacen el deshoje de la planta, pero así en el injerto no [....] están quedando atrás las mujeres en este trabajo, no hay cuadrillas de mujeres [...] quizás porque no se les ha dado la oportunidad (Miguel, 2017).

El injerto nace como un trabajo masculino, aunque objetivamente no requiere más esfuerzo o destreza que otros trabajos agrícolas, también realizados por mujeres. Se trata de un trabajo duro pero

9 Secretaría de Agricultura, Ganadería, Desarrollo Rural, Pesca y Alimentación en la República Mexicana 
bien pagado, un nicho apetecible en el trabajo vitivinícola que quizás por ello se mantiene como coto masculino.

¿El trabajo como injertadores de estos trabajadores qué consecuencias ha tenido en sus trayectorias sociolaborales? La respuesta varía según el trabajador y su familia resida en México o en Estados Unidos. Muchos de los miembros de la red viven en El Grullo y otros pueblos mexicanos, con desplazamientos temporales en función del trabajo. Varios de nuestros entrevistados declaran que pueden vivir todo el año con lo que obtienen en la temporada como injertador, sea en Europa o en el Valle de Napa, aunque la inmensa mayoría desarrolla otra actividad. En algunos casos, esta actividad es agrícola, como un injertador que combina su trabajo administrando siembras de caña en El Grullo con el injerto en Europa, junto con su hermano y mediante una empresa de servicios española.

En la mayoría de los casos, en particular entre los más jóvenes, con estudios medios, el dinero extra obtenido con el injerto se invierte en un negocio. En unos casos se trata de una boutique de ropa:

[...] tenemos un negocio, una boutique de ropa, con mi esposa... cuando iba a EE. UU. compraba ropa y cuando volvía, el resto del año, la vendía aquí [en El Grullo] también mi esposa trabaja para el Ayuntamiento y ya con eso ingresos [por injerto] nos ayudamos más (Luis, 2017).

En otros casos, el negocio es una "empresa de catering [...] yo y mi señora" (José, 2015) o se está ahorrando para una futura inversión. Es el caso de un joven de El Grullo y su futuro negocio turístico en la costa de Jalisco: "[el dinero] meterlo para los bungalows, haciendo los bungalows me iría muy bien, están cobrando 700 pesos por bungalows a los americanos, pero bueno hay que seguir trabajando" (Miguel, 2017). Unos y otros, con diversas modalidades, reproducen el imaginario de éxito del migrante mexicano (trabajar unos años en el extranjero, ahorrar e instalar un negocio propio). Además, otro destino del dinero obtenido injertando es pagar los estudios universitarios de hijos e hijas. En palabras de uno de ellos: "primero que nada, quiero darles una carrera a los dos, los que más aptitudes tengan, quisiera darles esa oportunidad" (Luis, 2017).

En el caso de los que viven en México, el trabajo de injertador supone una opción muy atractiva dentro del sector agrícola por los ingresos que perciben, las condiciones de trabajo y el trato recibido (respecto al de los trabajadores temporales no cualificados). Además, 
los ingresos obtenidos les permiten mejorar sus condiciones de vida (arreglar la casa o comprarse una) y, en muchos casos, al cabo de unos años establecer un negocio y dejar la actividad agrícola. Se puede hablar, de una movilidad sociolaboral ascendente para sí y, sobre todo, para los hijos e hijas (por la vía de los estudios).

Si se reside en Napa, u otro condado de California, el balance es menos positivo. Si bien los ingresos que obtienen en las campañas de injerto son buenos, superior a los que ganarían como jornaleros, no les permiten vivir de ese trabajo. El alto nivel de vida de Napa hace imprescindible otro trabajo para redondear ingresos, no ya para ahorrar sino para vivir. Por otro lado, a diferencia de México, entre los residentes en Napa la otra actividad laboral siempre es agrícola. Un injertador, residente en Santa Helena (condado de Napa), alternaba el trabajo en el injerto con el trabajo en una "vinatería", bodega, hasta que un reciente cambio de personal lo dejó sin trabajo, por lo que pasó a mantenimiento de jardines.

[...] pues trabajo, también tengo la opción de trabajar en los jardines, aquí que le llaman yardas, podando pastos y limpiando las casas o propiedades cuando se acaba el trabajo en temporada de injerto. Pues viviendo aquí, pues hay que buscar otra cosa, porque pues no puedo estar viviendo así nomás, porque aquí es muy costoso para vivir y estar sin trabajar, no se puede (Luciano, 2017).

Otros, con más suerte, formación específica y/o contactos, se emplean como trabajadores cualificados, por ejemplo, como tractoristas. Es decir, no salen del campo. En términos generales, los injertadores residentes en Estados Unidos no han conocido una movilidad laboral ascendente como sus paisanos que viven en México. Ellos no salen del campo aunque algunos de los hijos de estos injertadores sí lo han logrado, sobre todo los que nacieron en Estados Unidos o llegaron pequeños y se escolarizaron en ese país en una época de mayor apertura a la migración y de condiciones mejores de empleo, Tal es el caso del hijo de uno de los primeros injertadores que trabaja en una bodega y por ello no ha seguido el camino del injerto que le enseñó su padre. Además del diferente nivel de vida entre El Grullo y Napa y, por tanto, el distinto valor de lo ganado en la temporada de injerto, nuestros injertadores se enfrentan crecientemente en Napa a un mercado de trabajo más racializado y étnicamente segmentado, donde se acumulan las dificultades para que los migrantes mexicanos salgan del nicho del trabajo agrícola. 


\section{CONCLUSIONES}

Este artículo muestra el nacimiento y conformación de una red de injertadores mexicanos, surgida en Napa (California) pero nucleada alrededor de paisanos de El Grullo (México), que con el tiempo se consolida como red transnacional. Los pioneros de la red acertaron a detectar un nicho de trabajo especializado y mejor pagado que otros trabajos agrícolas, el injerto de calidad, ocupan dicho nicho y se consolidan como grupo de referencia por la calidad de su trabajo, primero en Estados Unidos y más tarde, principalmente, en los países vitivinícolas europeos. Como hemos visto, la red cumple tres funciones básicas para sus miembros: reclutamiento, enseñanza del oficio y, mediante sus contactos y el prestigio conseguido, inserción en los circuitos profesionales del injerto de calidad, tanto en Napa como a nivel internacional. En el desarrollo de la red, el Sr. Palma ocupa un lugar central. Ésta, como otras redes, es una red jerarquizada. Para futuras investigaciones es un aspecto a explorar considerando el análisis de la red en el marco de las relaciones desiguales dentro de la cadena de valor del vino.

Esta red de injertadores se inscribe en una diversidad y heterogeneidad de migraciones de trabajadores y profesionales transnacionales en el sector vitivinícola, con diferente estatus sociolaboral, migratorio y de condición étnica y de origen. Tanto en Napa, base de nuestro trabajo de campo, como en otras zonas vitivinícolas, podemos sintetizar esta heterogeneidad en tres tipos con implicaciones muy distintas para sus miembros: los más numerosos y más estudiados por la literatura, son los trabajadores para tareas no cualificadas, fundamentalmente la vendimia; un segundo tipo lo conforman trabajadores agrícolas especializados, como los injertadores; un tercer tipo compuesto por profesionales altamente cualificados, muy cotizados, como enólogos y otros, denominados "proficians".

La red de injertadores estudiada ostenta una posición intermedia entre los trabajadores de tareas manuales no cualificadas y los "proficians". Su característica fundamental es su "saber hacer" en una actividad muy especializada, el injerto de calidad, que es muy relevante para el segmento superior de bodegas. En este sentido, se asimilarían a los "proficians". Sin embargo, las diferencias son evidentes. A diferencia de otros trabajadores temporales agrícolas, los injertadores tienen buenos sueldos pero sus condiciones de trabajo, remuneración y consideración son distintas a las de los anteriores. 
Su trabajo es delicado, pero al mismo tiempo duro y penoso; trabajan a destajo y sin descanso semanal, lo que incumple el convenio del sector; los derechos y coberturas sociales derivados de su trabajo son limitados, dado su carácter temporal; además, en el caso de los que trabajan en Europa, la cotización a la Seguridad Social no tiene efectos en su lugar de residencia, sea México y/o Estados Unidos dado la falta de acuerdo entre los países a este respecto. Si bien se reconoce la especialización y calidad de su trabajo, los miembros de nuestra red de injertadores mexicanos continúan padeciendo un triple estigma: ser migrantes, ser mexicanos (y no de países desarrollados) y trabajar en el campo (el espacio social subordinado, menospreciado y racializado, dentro de la industria vitivinícola).

Otro aspecto que nos ha interesado y que marca diferencias, tanto respecto a las redes de trabajadores no cualificados como respecto a las de "proficians", lo representa las consecuencias del trabajo como injertador respecto a las trayectorias sociolaborales de estos trabajadores y sus familias. Aquí nuestra red de injertadores también ocupa una posición intermedia, aunque depende del lugar de residencia del trabajador. En el caso de los que viven en México, el trabajo de injertador supone una opción mucho más atractiva que otros trabajos agrícolas por los ingresos que perciben, las condiciones de trabajo y el trato recibido (en comparación con el de los trabajadores temporales no cualificados). Además, de mejorar su nivel de vida y el de sus familias, el trabajo como injertador les permite al cabo de unos años establecer un negocio propio, dejar la actividad agrícola si así lo desea, y sufragar los estudios universitarios de sus hijos e hijas. En este caso, podemos hablar de una movilidad sociolaboral ascendente para sí y, sobre todo, para los hijos e hijas (por la vía de los estudios).

Si se reside en Napa, u otro condado de California, la movilidad sociolaboral ascendente no está nada clara. Si bien los ingresos que obtienen como injertador son superiores a los que ganarían como jornaleros, no les permiten vivir de este trabajo. El alto costo de la vida en Napa hace imprescindible otro trabajo para vivir. Además, otra diferencia con los residentes en México es que la otra actividad laboral siempre es agrícola (otras tareas en los viñedos, mantenimiento de jardines o, en el mejor de los casos, se emplean como tractoristas u otros trabajos agrícolas cualificados). En términos generales, los injertadores residentes en Estados Unidos no han conocido una movilidad laboral ascendente como sus paisanos que viven 
en México. La razón, además de las obvias diferencias del costo de la vida, radica en nuestra opinión en el distinto contexto social. En Estados Unidos, nuestros injertadores se enfrentan a un mercado de trabajo racializado y un orden social segmentado étnicamente, donde es más difícil que los migrantes mexicanos tengan una movilidad laboral y social ascendente.

\section{BIBLIOGRAFÍA}

Achón, O. (2011). Importando miseria. La alternativa a la provisión de mano de obra agrícola. Madrid: La Catarata.

Berlan, J. P. (1986). Agriculture et migrations. Revue Européenne des Migrations Internationales, 2 (3), 9-32.

Bourdieu, P. (1980). Le capital social. Notes provisoires. Actes de Recherche des Sciencies Sociales, 31, 2-3.

Castles, S. (2000). International Migration at the Beginining of the Twenty-First Century: Global Trends and Issues. International Social Science Journal, 52, 269-281.

Corrado, A., de Castro, C., y Perotta, D.(eds) (2016). Migration and agriculture: Mobility and change in the Mediterranean area. London: Routledge.

Décosse, F. (2011). "Migrations sous contrôle. Agriculture intensive et saisonniers marocains sous contrat "OMI" ». Thèse de doctorat en sociologie. Paris: EHESS.

Durand, J. (2007). El programa bracero (1942-1964). Un balance crítico. Migración y Desarrollo, 9, 27-43.

Durand, J. (2014). Balance y prospectiva del fenómeno migratorio en México. [Versión digital]. Recuperado de http://repositorio.cualtos.udg.mx:8080/ jspui/bitstream/123456789/124/4/Balance\%20y\%20prospectiva $\% 20$ del\%20fen\%C3\%B3meno\%20migratorio\%20en\%20M\%C3\%A9xico.pdf

Durand, J. (2015). De programas bilaterales a visas unilaterales. Seis tesis sobre el trabajo migrante temporal. En S. Lara, J. Pantaleón, y M. J., Sánchez (Coords), Hacia el otro Norte. Mexicanos en Canadá (pp. 75-88). Buenos Aires: CLACSO.

Esteban, V., y López-Sala, A. (2010). En torno al mosaico canadiense. Una reflexión sobre la gestión política de la inmigración en Canadá. ARBOR Ciencia, Pensamiento y Cultura, CLXXXVI 744, 657-669.

García y Griego, M. (1988). The Bracero Policy Experiment: US.-Mexican Responses to Mexican Labor Migration, 1942-1955.Tesis de doctorado en Historia. Universidad de California - Los Angeles.

Glick S, N. Basche, L., y Szanton-Blanc, C. (1992). Towards a Definition of Transnationalism. Introductory Remarks and Research Questions. En N. Glick Schiller, et al. (Eds.), Towards a Transnational Perspective on 
Migration: Race, Class, Ethnicity and Nationalism Reconsidered, ( $p p . I X$ $X I V)$. New York: New York Academy of Sciences.

Gordo, M., y García, F. (2009). Explorando los contratos en origen en los campos españoles. Huelva: Universidad de Huelva.

Heredia, M., y Poblete, L. (2013). La estratificación socio-laboral en un caso de globalización exitosa: la vitivinicultura mendocina (1995-2011). [Versión digital] Mundo Agrario, 14 (27). Recuperado de http://www.mundoagrario.unlp.edu.ar/.

Lamanthe, A. (2015). Modalidades y marcos jurídicos en la contratación de trabajadores temporales en Europa. En M. J. Sánchez y S. Lara (Coords.), Los programas de trabajadores agrícolas temporales: ¿Una solución a los retos de las migraciones en la globalización? (pp.237-257). México: Instituto de Investigaciones Sociales, UNAM.

Martin, P., Taylor, E., y Hardiman, P. (1988). California Farm Workers and the SAW Legalization Program. [Versión digital] California Agriculture, november, december. Recuperado de < http://calag.ucanr.edu/ archive/?type $=$ pdf\&article $=$ ca.v042n06p4.

Miller, M., y Martin, P. (1982). Administering Foreign Worker Programmes: Lessons from Europe. Lexington MA: Lexington books.

McLean, R. (2013). Wine, Meaning, and Place: Terroir-Tourism, Concealed Workers, and Contested Space in the Napa Valley. Tesis de doctorado. Universidad de California - Santa Bárbara.

Mésini, B. (2015). Le détachement transnational dans l'agriculture européenne. Circulations du capital humain et financier entre pays d'origine, d'accueil et de mise à disposition. [Versión digital] Anthropology of food S11. Recuperado de http://aof.revues.org/7892

Michalon, B., y Potot, S. (2008). Quand la France recrute en Pologne. Réseaux transnationaux et main-d'œuvre agricole. Etudes rurales, 182, 87-102.

Mines, R. (2013). Jornaleros mexicanos en California: el cambiante mercado laboral agrícola. Carta Económica Regional, 25, 87-111.

Moreno, J. (2012). Movilidad transnacional, trabajo y género: temporeras marroquíes en la agricultura onubense. Política y Sociedad, 49-1, 123-140.

Morice, A., y Michalon, B. (2008). Les migrants dans l'agriculture: vers une crise de main-d'œuvre?. Etudes rurales, 182, 9-28.

Morilla, J. (2001). Cambios en las preferencias de los consumidores de vino y respuestas de los productores en los dos últimos siglos. En J. Carmona, J. Colomé, J. Pan-Montojo, y J. Simpson. Viñas, bodegas y mercados: El cambio técnico de la vitivinicultura española 1850-1936 (pp. 13-38). Zaragoza: Prensas Universitarias de Zaragoza.

Nichols, S. (2006). Santos, duraznos y vino. Migrantes mexicanos y la transformación de los Haros, Zacatecas y Napa, California. México: Universidad Autónoma de Zacatecas/Miguel Ángel Porrúa.

Pan-Montojo, J. (2009). Las viticulturas europeas: de la primera a la segunda globalización. [Versión digital] Mundo Agrario, 9(18). Recuperado de http://www.scielo.org.ar/pdf/magr/v9n18/v9n18a08.pdf. 
Portes, A. (1995).The Economic Sociology of Immigration. Essays on Networks, Ethnicity and Entrepeneurship. New York: Russell Sage Foundation.

Portes, A., Guarnizo, L., y Landolt, P (1999). The Study of Transnationalism: Pitfalls and Promise of an Emergent Research Field. Ethnic and Racial Studies, 22 (4), 218-237.

Preibisch, K. (2015). Los trabajadores migrantes y los cambios en los regímenes laborales en la producción agrícola contemporánea de Canadá. En S. Lara, J. Pantaleón, y M. J., Sánchez (Coords), Hacia el otro Norte. Mexicanos en Canadá (pp. 115-138). Buenos Aires: CLACSO.

Reigada, A. (2015). ¿Cultivos de primor? Feminización y sexualización del trabajo en los campos de fresa de Andalucia. En M. J. Sánchez y S. M. Lara (Coords), Los programas de trabajadores agrícolas temporales: ¿Una solución a los retos de las migraciones en la globalización? (pp. 319-354). México: Instituto de Investigaciones Sociales, UNAM.

Sánchez, M. J. (2004) Caracterización sociodemográfica de los mexicanos que trabajan en la agricultura en los condados de Napa y Sonoma, California. En M. Favela y R. Delgado Wise (Coords), Nuevas tendencias y desafíos de la migración internacional México-Estados Unidos (pp. 127144). México: CEICH-UNAM, Universidad Autónoma de Zacatecas, Miguel Ángel Porrúa librero editor.

Sánchez, M. J. (2007). Trayectorias migratorias y laborales de mexicanos que trabajan en la agricultura en los condados de Napa y Sonoma, California. En M. I. Ortega, P. A. Castañeda y J. L. Sariego (Coords), Los jornaleros agrícolas, invisibles productores de riqueza: Nuevos procesos migratorios en el noroeste de México (pp. 197-226). México: Plaza y Valdés editores CIAD - Ford Foundation.

Scott L.,y Urry J.(1994). Economies of Signs and Space. London: Sage.

Trigueros, P. (2015). La contratación de trabajadores agrícolas con visas H2A. Del Programa Bracero a la situación actual. En S. Lara, J. Pantaleón, y M. J., Sánchez (Coords), Hacia el otro Norte. Mexicanos en Canadá (pp. 173-206). Buenos Aires: CLACSO.

Tomic, P., y Trumper R. (2018). Vino, racialización y neoliberalismo en el valle del Okanagan en Canadá. En M. J. Sánchez, F. Torres e I. Serra (coords.), Transformaciones productivas, inmigración y cambios sociales en zonas vitivinícolas globalizadas (pp. 183-213). México: Instituto de Investigaciones Sociales.

Torres, T., Allepuz, R., y Gordo, M. (2014). La contratación de mano de obra temporal en la agricultura hortofrutícola española. Ager. Revista de Estudios sobre Despoblación y Desarrollo Rural, 16, 7-37.

United States Department of Agriculture (USDA). (2014). 2012 Census of Agriculture. United States. Summary and Stata Data, Volume 1. Geographic Area Series, Part 51, Estados Unidos: National Agricultural Statistics Service. Disponible en: https://www.agcensus.usda.gov/Publi cations/2012/Full_Report/Volume_1, Chapter 2_US_State_Level/usvl. pdf. 
United States Department of Agriculture (USDA). 2012 Census of Agriculture. Volume 1, chapter 2: County Level Data. Estados Unidos: National Agricultural Statistics Service. Disponible en: https://www.agcensus. usda.gob/Publications/2012/Full_Report/Volume_1_Chapter_2_County_Level/California/.

Verduzco, G. (2015). El PTAT y los programas de trabajadores temporales. Una visión crítica. En S. Lara, J. Pantaleón, y M.J., Sánchez (Coords), Hacia el otro Norte. Mexicanos en Canadá (pp. 89-114). Buenos Aires: CLACSO.

Vézina, C. (2015). Dinámica de la emigración laboral durante el Programa Bracero: una mirada histórica. En M. J. Sánchez y S. M. Lara (Coords), Los programas de trabajadores agrícolas temporales: ¿Una solución a los retos de las migraciones en la globalización? (pp. 145-172). México: Instituto de Investigaciones Sociales, UNAM.

Viruela, R. (2016). La movilidad interna e internacional de los inmigrantes rumanos durante la crisis. Scripta Nova: Revista electrónica de geografía y ciencias sociales, 20, 527-551.

Waldinger, R. (2013). Immigrant transnationalism. Current Sociology, 61, 756-777.

Zabin, C., Kearney, M., García, A., Runsten, D.,y Nagengast, C. (1993). New Cycle of poverty: Mixtec Migrants in California Agriculture. Davis, California: California Institute for Rural Studies.

Zelinsky, W. (1971). The hypothesis of the mobility transition. Geographical Review, LX1, 219-249. 